\title{
Introduction: Foundational considerations in balancing innovatory processes and sustainable development practices in comparative light
}

\section{John R. McIntyre, Silvester Ivanaj and Vera Ivanaj}

This book of expert and scholarly contributions on strategies for sustainable technologies and innovations is the by-product of the three-day international conference (Multinational Enterprises and Sustainable Development - MESD'09) held at Nancy, France, in November 2009, jointly organized by the ICN Business School (France), the CEREFIGE research center of the Université de Lorraine (France), and the Georgia Tech Center for International Business Education and Research, Georgia Institute of Technology, Atlanta, USA.

The conference brought together academics, research-oriented practitioners, experts, consultants and various professionals in the field of technology management for sustainable development with a view to refine our understanding of one of the major challenges of our environmental future: its innovation dimensions. Our conviction is that the form in which business operations are actually conducted around the world cannot be sustained, as momentous changes continue to characterize our planet. Scientific evidence points to the fact that human and organizational behaviors can result in critical damage to our natural systems. The quality of human existence continues to be strongly related to our ability to innovate and to conceive sustainable technological and productive systems. Radical socio-technical changes are needed to slow and eventually reverse the deterioration of our environment, but also to develop available natural resources. Business firms are catalysts and agents of societal and economic change. Over the last decade, companies have faced social and environmental pressures to better integrate the challenges of sustainability. Scholars, policy-makers and experts, among others, have argued that sustainable development is the perfect opportunity for businesses to strengthen the evolving notion of corporate social responsibility, 
while achieving long-term growth through the innovatory process and capitalizing on research and development. Companies that ignore these opportunities do so at their peril. But companies have had considerable difficulties in addressing the opportunities inherent in the challenge of sustainable development. In particular, their technological and innovation strategies are often inappropriate to manage the complex and the uncertain nature of this new demand. Corporate strategies that integrate the goals of sustainability are urgently needed.

Given the ever-changing global economic environment and the challenges raised by the legal process, strategic choices for technology and innovation have become key factors for success in implementing sustainable development policies. The economic growth and competitiveness as well as the societal well-being of businesses can be predicated on these choices and policies.

This book focuses on the issue of strategies for innovation-driven sustainable technologies. It seeks to address the following major questions regarding sustainable development: Why, when, and how will such strategic technological and innovatory choices be made and deployed? Can enterprises make technological choices that will be economically advantageous, ecologically sustainable and socially responsible? How do corporations balance and harmonize their choices, considering the elements of technological innovation, economic growth, resource efficiency and environmental protection? Do contextual, economic, ecological or societal factors play a role in economic and financial profitability, competitiveness, market openness, policies, technical standards and regulations? Are there international differences that bear noting and have some explanatory power? Are current decisions an adequate response to anticipated future needs? What is the relationship between technological strategies employed by businesses and a country's or a sector's economic performance? How do enterprises employ strategic analysis in order to compare the negative impacts of present-day technologies with the positive benefits of future innovations?

These questions are at the core of sustainable strategic management and apply to management scholars, economists, lawyers, sociologists and individuals in all the relevant engineering fields. It must be reiterated that while multinational corporations have been at the forefront of sustainable development, the role of small and medium-sized enterprises cannot be undermined as they respond to the broad trends set in motion by larger firms. Nor can the ethical dimension of such choices, strategies and modes of implementation be ignored as they frame the debate. Technology sets the production frontier, and should be viewed as a neutral factor, often resulting from the political stakes of public and private decision-makers. 
Our book seeks to provide guidance to enterprises of all sizes and to organizational decision-makers seeking sustainable technology and innovation-driven solutions. The purpose of the authors and of the entire volume is to explore and share ways in which business firms can bring their technology and innovation strategies in closer alignment with the requirement of sustainability.

The book is structured in two parts, each of which deals with a specific aspect of sustainable technology and innovation systems: 'Part I: Building sustainable technology and innovation systems', and 'Part II: Strategic implications and assessment'.

\section{PART I: BUILDING SUSTAINABLE TECHNOLOGY AND INNOVATION SYSTEMS}

The six chapters in Part I address the relationship between sustainable technology and innovation in the context of global socio-economic systems. The core idea is that sustainable technologies and innovations must benefit both companies and global economic and social development. Innovation can be a value-creating process and can integrate social needs more fully through a radical, or at least momentous, cultural change by empowering both customers and employees. This process of innovation has evolved a transformation in which multinational corporations of necessity will play a central role responsive to a more globalized regulatory system. Moreover, life philosophy, beliefs and values of the world community will also shape sustainable technologies and innovation systems.

In Chapter 1, Paul Shrivastava examines how sustainable innovation constitutes a useful response to global climate change. Climate change is rooted in human activities, many of which are directly controlled by corporations. Sustainable innovations can assist companies in improving their ecological and social performance and gaining competitive advantage. He shows that a mindful application of appropriate technologies and rational use of resource conservation by companies can yield large gains in performance. This, he claims, can happen with respect to a company's vision, inputs, throughputs and outputs. Past literature associates technological innovations with 'high-tech', and large research and development (R\&D) budgets. Shrivastava asserts that this is not necessarily the case. Sustainable innovations can take simple rationalization approaches, de-bureaucratizing organizational procedures and conserving renewable resources sensibly. He provides several examples of sustainable innovations in main-line companies such as General Electric, Walmart, 3M Corp, United Parcel Service of America Inc., and others. Sustainable 
innovations can also be facilitated by empowering customers and employees to eliminate wasteful practices in areas where small benefits can be magnified by frequency of use.

In Chapter 2, 'Understanding eco-innovation for enabling a green industry transformation', Tomoo Machiba elaborates a theoretical framework of eco-innovation by taking stock of the extant knowledge, and proposes a fresh perspective for more comprehensive analyses in the future. The chapter first outlines a context of green growth and eco-innovation in the past two decades since sustainable development emerged as a global policy discourse. Green growth can be considered as a new strategy to revive the sustainability agenda and to integrate it practically into mainstream policies as well as industry activities.

Green growth generally entails decoupling economic growth from environmental degradation. However, in many areas, environmental pressures continue to rise as economies grow, and improvements in efficiency have often been offset by increasing consumption and outsourcing. The challenges cannot be met by business as usual. In this chapter, eco-innovation (or sustainable innovation) is given as a key factor to enable the decoupling. Diverse types of eco-innovation exist including both the creation of new technologies, products and processes, as well as their application and diffusion. Synthesizing the existing understanding and definitions, the author proposes to analyze eco-innovation based on a three-dimensional framework that consists of an innovation's target, mechanism and impact.

An examination of corporate sustainable production activities through this proposed framework indicates that the primary focus of current eco-innovation tends to rely on technological advances, typically with products or processes as eco-innovation targets and with modification or redesign as principal mechanisms. Nevertheless, a number of complementary organizational or institutional changes have functioned as key drivers for these developments, such as the setting up of intersectoral or multi-stakeholder collaborative networks. The author argues that a sophisticated combination of different types of innovation could bring far-reaching changes in the techno-social system and enable a long-term green transformation by impacting several components of the economy including consumers.

Among the key social, technical and political elements in determining the success of eco-innovation, particular attention is paid to the 'business model', which drives eco-innovation to the market and enables its diffusion. The business model perspective allows a deeper and more subtle understanding of how environmental value is captured, turned into profitable products and services, and can deliver convenience and satisfaction to users. It is particularly relevant to radical and systemic eco-innovation as 
it also makes for a sharper understanding of eco-innovation as one of the paths to restructure the value chain, producer-consumer relationships and evolving consumer practices.

Lastly, the role of diverse policy instruments in the acceleration of ecoinnovation is reviewed. Many radical and systemic solutions have been facing rather high entry barriers since they do not always fit the existing technology systems and need long-term investment in the development of new infrastructures as well as cultural changes. To break the technological lock-in and path-dependencies, policy decisions made today need to incorporate a longer time horizon and governments need to take a stronger leadership position in actively supporting infrastructure and platform development. Exemplars of these include the development of smart grids, public transport systems and green cities.

In Chapter 3, Corinne Gendron argues that sustainable development has been discussed for decades now, but its relationship to the national economy still remains unclear, and even controversial. With the new concept of the 'green economy', the United Nations Environment Programme (UNEP) is proposing an insightful clarification about the role it must play to reorient our societies towards sustainable development. Building on the Porter hypothesis, the UNEP report supports a green and inclusive growth enabled and potentiated by innovation. But to play such a central role, technology has to be driven by societal needs through a process of transition management. This requires deepening our understanding of the relationship between innovation and social and cultural changes which may constitute more powerful drives than traditional technology.

In Chapter 4, 'Appraisal of corporate governance norms: evidence from Indian corporate enterprises', Rabi Narayan Kar reviews how the issues relating to corporate governance have come into prominence because of their evident importance to the sustainable health of corporations as well as society in general, in the context of the plethora of corporate scams and debacles in the recent times. The United States (US), Canada, the United Kingdom (UK), European countries, East Asian countries and India have all experienced several pressures on their economic well-being and have faced the ever-widening impact of the Great Recession of 2008 in its global dimensions, leading to the demise of several of their leading companies. Already a greater emphasis on corporate governance issues has been set in motion. Corporate governance broadly refers to a set of strategies and best practices designed to govern the behavior of corporate enterprises and light their path in a forecasting perspective. Corporate governance deals with laws, procedures, practices and implicit rules determining a company's capacity to make managerial decisions endowed with 
a long-term perspective and to implement innovative strategies oriented to sustainable growth. In this context, governments all over the world are playing the role of facilitators by supporting, and often promoting, good corporate governance as well as the ethical functioning of corporate enterprises. This chapter analyzes the regulatory framework of the corporate governance system in India. The case study of Satyam Computers has been incorporated to sharpen our grasp of the issues and to draw out insightful comparisons with other corporate failures.

Chapter 5 authored by Tagi Sagafi-nejad tracks the evolving relationship between multinational enterprises (MNEs) or transnational corporations (TNCs) and governments, from the 1970s when a protracted exercise under United Nations (UN) auspices to establish a code of conduct for MNEs was ultimately abandoned, and through the 1980s when an OECD initiative to establish a multilateral agreement on investments was likewise given up. At the dawn of the twenty-first century, and in the wake of the 2008 global financial crisis, the need for multilateral instruments to delineate boundaries and establish rules of engagement for MNEs and nation-states re-emerged with momentous salience. What can be learned from earlier attempts to establish such rules? Has the time come for promulgating some form of international accord concerning the entire gamut of nation-states' relations with these enterprises? The chapter draws parallels between the turbulent 1970s and the current uneasy relations between nation-states and TNCs, and explores the extent to which lessons learned during the earlier period can lead to a better understanding of the more complex and nuanced international business environment of the twentyfirst century. The chapter asserts that earlier attempts to establish such rules are fraught with actionable lessons, and concludes that the time has come to evolve some form of international accord concerning the entire gamut of nation-states' relations with multinational border-crossing enterprises.

Sanjeeb Kakoty in Chapter 6, 'Appropriate technology movement', examines how history and human experience highlight the preponderant influence of leading technologies in succeeding periods of time. Interestingly, the essential fabric of human life and social mores was often built around the predominant technology extant during that time. But the question that arises is: What determines the choice of technology? Does technology arise due to the specific physical needs of the community? Is technology in turn shaped and influenced by the philosophy, religious beliefs and worldview of a particular leading community? In this scenario, what kind of impacts would imported technology have on the specific need mitigation of the community, and also on their philosophy of life? Would it be possible and feasible to have a uniform technology for all regions of 
the world, or would it be more suitable for disparate regions and individual communities to develop their own unique region-specific technologies? This is the crux of the appropriate technology movement. Schumacher is considered to have exerted the preponderant influence on the movement by formulating compelling arguments for small-scale, decentralized, environmentally sustainable enterprises. He, in turn, was greatly influenced by the votary of truth and non-violence Gandhiji, who felt that economics and ethics were two sides of the same coin. These thoughts are also a reflection of Hindu and Buddhist traditions.

By the dawn of the new millennium, serious doubts had emerged about the rationale behind man seeking perpetual economic growth through rapid industrialization, often ignoring the human and environmental costs. What resulted was a search for an alternative blueprint for progress. This model had to be based on the use of appropriate technology which involved taking cognizance of local needs, conditions and aspirations. Interestingly, these considerations automatically brought with them the principles of sustainability and best business practices.

\section{PART II: STRATEGIC IMPLICATIONS AND ASSESSMENT}

The seven chapters contained in Part II deal with the contextual factors defining how to implement sustainable technologies innovation. Macroeconomic factors such as the economic level of the country development, or microeconomic ones such as business size and the industry organization, are taken into account. Part II of the book focuses on how effective innovation and technology strategies can be crafted in developing countries, and also for smaller businesses or entrepreneurs. Innovative business opportunities exist not only for core organizational functions such as product innovation, but also for different support functions, such as the supply chain and logistics.

Chapter 7, 'Eco-social business in developing countries: the case for sustainable use of resources in unstable environments', authored by Roland Bardy and Maurizio Massaro, explores how the concept of eco-social business, generating productive employment opportunities while supporting a responsible use of natural and non-renewable resources in developed countries, can be applied to emerging and transition economies; and how this approach can be buttressed through foreign direct investment (FDI) or other forms of border-crossing business interventions. The authors take up the question whether a realistic and effective business strategy addressing the issue of sustainable use of resources in the developing world is 
possible. They argue that business opportunities can be found for most investors in developing economies, either through creating new markets with appropriate innovative products or services, or through new forms of production and by building local capabilities utilizing local natural resources. The chapter further demonstrates which research domains must be brought together, offering a conceptual framework for eco-social business in developing economies.

Chapter 8, 'Entrepreneurship development at a small scale: a key to sustainable economic development', authored by Sanjay Bhāle and Sudeep Bhāle, looks into the power of collective efforts made at a small scale and how they can be converted and scaled to a large, sustainable, growing business supportive of grass-roots initiatives and actors. A case study is also presented, 'A modest testimony', on how an organization started by seven women with a sum of less than US\$2 grew over a period of years into a multi-million-dollar organization. This example is illustrative of the paradoxical notion that 'small is big'. The chapter also advances some basic fundamentals of social entrepreneurship (SE) and how social entrepreneurship can contribute to sustainable development of societies. The 'key features of social entrepreneurship' embedded in this chapter provide some productive insights to this new emerging field of entrepreneurship, capturing salient attributes related to social entrepreneurship, and offering examples of great work in this area. Overall this chapter is a demonstration of the varied possibilities evident in different economies to build a sustainable economic environment by bringing together the right mix of ideas, effort and entrepreneurial attributes.

In Chapter 9, 'Entrepreneur profile and sustainable innovation strategy', Sandrine Berger-Douce and Christophe Schmitt describe a specific project illustrating a sustainable innovation strategy. That issue concerns the study of social responsibility and innovation in small and mediumsized enterprises. Among the multiple issues involved in sustainable strategies, Chapter 9 focuses on the reasons why economic representatives choose to carry out these strategies. In small and medium-sized enterprises, the literature shows that the entrepreneur's profile is a dominant influence on strategic choices. This chapter analyzes this relationship in some depth. A case study was conducted at Ecodas, a small business located in northern France. Created in 2000, the firm is specialized in the design and manufacturing of medical waste treatment machines using shredding and sterilization technologies. The case of Ecodas illustrates how to reconcile economic performance with ecological respect and social responsibility, in accordance with the international norm ISO 26000 published at the end of 2010. The authors report that the key factors for a sustainable innovation strategy for small businesses are based on ele- 
ments of the entrepreneur's profile (social capital, audacity and tenacity) supported by a favorable regulatory environment. In other words, this chapter underlines the necessity to combine an entrepreneur's profile with a favorable environment in order to succeed with the sustainable technology-oriented innovations.

Chapter 10, 'Benchmarking sustainable construction technology in the building and transportation sectors', authored by Salwa Beheiry and Ghassan Abu-Lebdeh, deals with the principles of benchmarking sustainable construction technologies and techniques in the building and transportation sectors. This industry sector targets residential and commercial property and transportation projects, including roadway, bikeway and walkway segments; junctions including roundabouts, bridges including piers, signalized and non-signalized intersections, tunnels, runways, taxiways and holding areas; and facilities including bus stops and rail and metro stations, and transfer points and pavements. The chapter also discusses process benchmarking as a vital tool in measuring the performance of capital projects and, in recent years, also in measuring the advancement of sustainable technologies and tools in building and transportation projects. Benchmarking provides organizations with a means to gather information about the current levels of application of sustainability practices and technology integration in project execution. Furthermore, the chapter gives insight into the evolving progress of the sustainability movement in the different engineering sectors. Chapter 10 also discusses a sustainable technology benchmarking case study, using a pilot data sample and a follow-up data sample of residential and commercial buildings in the United Arab Emirates. It is this type of industry-specific study that can strengthen and empirically confirm the theoretical constructs articulated in this text.

Chapter 11, authored by Thierry Houé and Renato Guimaraes, argues that key elements of the optimization of supply chains and transportation policy are necessarily linked with the sustainable development strategy of companies. This chapter considers the integration of inland waterway transport within the supply chain organization implemented by sustainable firms. Through a literature review and some practical examples based in the French context, it tries to demonstrate how the use of waterways, especially in combined transport operations, leads to an improvement of sustainable and innovative practices for supply chain management. However, even if eco-logistics processes are often presented as a considerable asset, their complexity is likely to generate significant and, at times, prohibitive costs and risks. These pages also look at the need for companies to consider new sustainable solutions to manage their flows, taking into account the complexity of today's international 
logistics and the nature of the product transported. On the one hand, the chapter concludes that the key factors for success of this integration are related to improved relationships between the different players in the global supply chain (shippers, logistics services providers, and so on) and to reorganizing models of transport. On the other hand, it shows that the use of inland waterway transport cannot be generalized without a strong political will but also an expansion of dedicated and sustainable multimodal services.

In Chapter 12, 'Integrating sustainability and technology innovation in logistics management', Matthias Klumpp, Sascha Bioly and Stephan Zelewski discuss the prima facie conflict between technological innovation and sustainability in logistics. The authors provide an introduction to the logistics market and growth of the value-added service industry of logistics and supply chain management. They also show that in specific situations, warehouse centralization sustainability is hard to achieve today, based on existing information and cost structures. They consider the example of enhanced transparency in the supply chain, for example using innovative radio-frequency identification (RFID) technology to build sustainable logistics solutions. This research contribution urges logistics managers involved in long-term plans and projects to integrate a sustainability perspective into their investment calculations as sustainability on an operational level is largely dominated by long-term investments, that is, warehouse and plant locations or transport network structures.

Finally, Chapter 13, 'Sustainable development, a new source of inspiration for marketing innovation?' by Gaël Le Boulch and Rémy Oudghiri argues that while 46 percent of the French feel that their companies do not do anything for the environment, politicians increasingly seem to take sustainable development issues into account. In the US under the leadership of President Barack Obama, and in Europe where green movements have made a significant breakthrough in the recent European elections, this issue is high on the policy agenda, more than a mere fad. Nevertheless, companies - whatever their size - seem to have some difficulty in revising their business models and assumptions. How are companies to integrate sustainable development in the business processes and not to reduce it to a pure marketing tool? The truth is that customers and consumers often perceive an egregious lack of commitment. This chapter aims to present five ways to implement sustainable development in companies. How are companies to assure that sustainable development impacts directly on the corporate bottom line and is an organic part of their innovation strategy? This chapter finally considers how a major public company can reinvent itself and its client relations through innovative sustainable development decisions. 


\section{CONCLUSIONS}

This book has the merit of addressing how researchers and practitioners think through the complex nexus of sustainable technology and innovation questions, from theoretical, regional, corporate and industry 'best practices' perspectives.

Selected contributors have argued that we can make technology and innovation choices that are profitable for firms and promote economic development for countries in development while balancing the environmental protection and social progress equities. Companies in developed and emerging countries are conceiving and implementing sustainable strategies, taking into account contextual factors to find appropriate ways of doing business that do not harm the Earth's natural equilibrium. Profitability oriented strategies as well as ecologically conscious strategies, as is argued and demonstrated, can converge toward a more holistic process of doing business. As a consequence, research and empirical methodologies which describe and explain the range of multidimensional influences are essential building blocks to achieve balanced sustainability strategies supported by the innovatory process. 
John R. McIntyre, Silvester Ivanaj, and Vera Ivanaj - 9781781006832 Downloaded from PubFactory at 04/26/2023 10:10:16AM 